\title{
Pesticides in the Environment and Mitigation Technologies
}

\author{
Marcela Levio ${ }^{1}$, Edward Hermosilla ${ }^{1}$ and Cristina Diez $\mathbf{M}^{1,2 *}$ \\ ${ }^{1}$ Biotechnological Research Centre Applied to the Environment, La Frontera University, Chile \\ ${ }^{2}$ Department of Chemical Engineering, La Frontera University, Chile
}

Submission: March 3, 2019; Published: March 14, 2019

*Corresponding author: Cristina Diez M, Biotechnological Research Centre Applied to the Environment and Department of Chemical Engineering, La Frontera University, Chile

Abstract

This widespread use of pesticides for agricultural and non-agricultural purposes has resulted in the presence of their residues in various environmental matrices. The contamination could be on-farm during pesticides manipulation or by wastewaters generated by agroindustrial activities and could be treated efficiently in a biopurification system. This technology with some modifications can be used for treating obsolete pesticides and pharmaceuticals products.

Keywords: Biopurification System; Pesticides; Pharmaceuthicals

Abbrevations: BPS: Biopurification systems; WRF: white-rot fungi; OTC: oxytetracycline; CFN:carbofuran

\section{Introduction}

The worldwide consumption of pesticides is more than two million tons per year, been Europe the major consumer (>45 \%) followed by USA (>25\%) and the rest of the world (25\%) [1]. Worldwide consumption of pesticides is: herbicides $(47.5 \%)$, insecticides (29.5\%), fungicides (17.5\%) and others (5.5\%) [2]. The World Health Organization (WHO) states that each year occur in the world's 25 million pesticide poisonings in which 20 thousand people die. On the other hand, the United Nations Food and Agriculture Organization (FAO), reports that while $80 \%$ of pesticides spread over the world are used in developed countries, $99 \%$ of poisonings occur in developing nations (Figure 1).

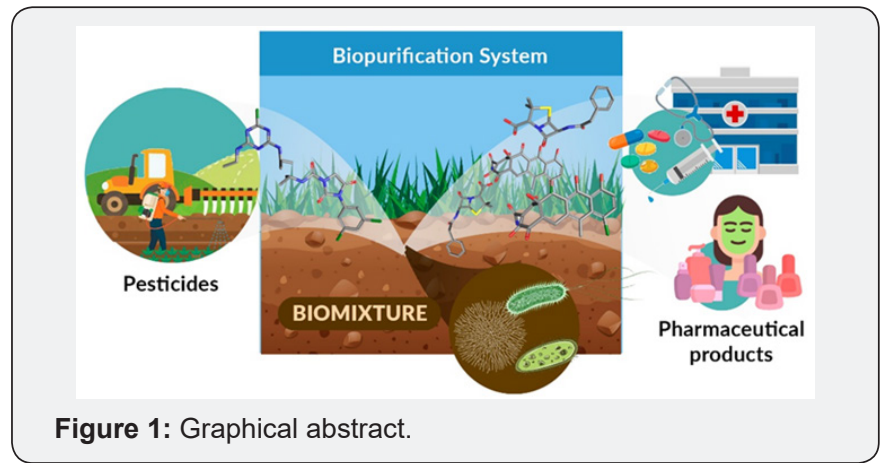

Pesticides compounds are toxic chemicals that can adversely affect people, animals, wildlife and desirable plants, besides to target pests [3]. Many of pesticides compounds are hydrophobic or moderately hydrophobic, with a complex chemical composition which makes its degradation in the environment difficult. As a consequence, pesticide residues and their transformation products are frequently found in groundwater and surface waters. The contamination could be during on-farm pesticides manipulation (filling equipment) or by wastewaters generated by industrial activities associated with the agriculture and forestry. Wastewaters from the fruit-packaging industry with high pesticide loads (50-1000 mg L-1) have been reported by Karas et al. [4].

Also, from industries related to manufacturing, packaging, transporting, storing and distribution of pesticides. In manufacturing and formulation and packaging, pesticide wastewaters can be generated from formulation equipment cleanup, spill wash-down, drum washing, air pollution control devices, area runoff and laboratory drains [5]. On-farm, pesticide residues remain in the containers and application equipment after pesticides are applied to target areas. These residues are removed by rinsing with water resulting in the formation of a toxic wastewater that represents a disposal problem for many farmers. Another important source of pesticides contamination is the production of forbidden and expired pesticides [6]. Obsolete pesticides are defined as pesticides that have been banned, they are chemically damaged, outdated, that are unknown or have fallen into disuse. 
Globally, the amount of obsolete pesticides exceeds 500 thousand tons and of these about 30 thousand tons are in Latin America (International Bank for Reconstruction and Development, (2010). Biopurification systems (BPS) were developed to reduce the environmental pollution due to onfarm point-source contamination mainly caused by spilling or washing water from pesticide application equipment's [5,7]. Also, for the treatment of agroindustrial wastewaters containing pesticides $[5,8]$.

They are based on adsorption and degradation processes on a biomixture, formulated with soil, peat and straw or agroindustrial residues and eventually inoculated with pesticidesdegrading microorganisms [9-13]. Rodriguez et al. [14] summarize the potential participation of white-rot fungi (WRF) in BPS and describe the enzymatic systems involved in pesticides degradation. Besides, the authors present an outline of BPS, focusing on the elements that influence the participation of WRF in their operation and studies regarding the fungal-mediated degradation of pesticides in BPS biomixtures.

\section{Discussion}

Several studies have demonstrated that BPS can effectively retain and degrade pesticides [7]. Niels et al. [15] evaluated the degradation and leaching of 21 pesticides and they determined than no traces of 10 out of 21 applied pesticides were detected in the percolate. The BPS has been tested to degrade a mixture of pesticides with repeated applications with high efficiency and has been demonstrated that $>$ a $90 \%$ of the products were degraded in the BPS, decreasing the half-life of the products compared with their degradation in soils $[16,17]$.

Recently, the BPS has been used as a new alternative to treat wastewater contaminated by emergent contaminants. These compounds are potentially harmful for humans and ecosystem. We can mention, pharmaceutical products, drinking water and swimming pool disinfection products, sunscreens and UV filters, flame retardants, benzothiazoles, etc. [18]. In this sense, Jimenez et al. [19] studied the capacity of the system to dissipate oxytetracycline (OTC) in a biomixture previously used for carbofuran (CFN) removal obtained that different doses of OTC did not significantly affect CFN mineralization. They concluded that this biomixture can be re-use as a support material for wastewater treatment of this type of contaminant. Similar behaviour was found by Cambronero et al. [20], who employed a fungal pre-treatment of OTC rich wastewater, before its disposal in a BPS used for the treatment of two pesticides. They demonstrated a high efficiency of the biomixture to remove pesticides, and indicate that the fungal pre-treatment of OTC containing wastewater was not required before its disposal in the BPS

\section{Conclusion}

The biopurification system is an adequate and efficiently technology to degrade complex molecules of pesticides in single and repeated applications. This technology can be used efficiently to treat emerging contaminants along with pesticides in an unique system, preventing soil and water contamination.

\section{Acknowledgments}

This work was supported by FONDECYT № 1161481 and CONICYT/FONDAP/15130015 projects and, GAP-UFRO 2017.

\section{References}

1. De A, Bose R, Kumar A, Mozumdar S (2014) Targeted delivery of pesticides using biodegradable polymeric nanoparticles pp. 59-81.

2. Pathak R, Dikshit A (2012) Atrazine and its use. International Journal of Research in Chemistry and Environment 2: 1-6.

3. Wilson C, Tisdell C (2001) Why farmers continue to use pesticides despite environmental, health and sustainability costs. Ecological Economics 39(3): 449-462.

4. Karas PA, Perruchon C, Exarhou K, Ehaliotis C, Karpouzas DG (2011) Potential for bioremediation of agro-industrial effluents with high loads of pesticides by selected fungi. Biodegradation 22(1): 215-228.

5. Karanasios E, Tsiropoulos NG, Karpouzas DG (2012) On-farm biopurification systems for the depuration of pesticide wastewaters: recent biotechnological advances and future perspectives. Biodegradation 23(6): 787-802.

6. Dasgupta S, Meisner C, Wheeler D (2010) Stockpiles of obsolete pesticides and cleanup priorities: A methodology and application for Tunisia. J Environ Manage 9(1): 824-830.

7. Castillo MP, Torstensson L, Stenstrom J (2008) Biobeds for environmental protection from pesticide use - A review. J Agric Food Chem 56(15): 6206-6219.

8. Lizano V, Masís M, Espinoza D, Lizano M, Rodríguez C (2017) Removal of pesticides and ecotoxicological changes during the simultaneous treatment of triazines and chlorpyrifos in biomixtures. Chemosphere. 182: 106-113.

9. Karanasios E, Tsiropoulos N, Karpouzas D, Ehaliotis C (2010) Degradation and adsorption of pesticides in compost-based biomixtures as potential substrates for biobeds in Southern Europe. J Agric Food Chem 58(16): 9147-9156.

10. Diez MC, Tortella G, Briceño G, Castillo MP, Diaz J, et al. (2013) The influence of novel lignocellulosic residues in a biobed biopurification system on the degradation of pesticides applied in repeated high doses. Electronic Journal of Biotechnology 16(6): 1-12.

11. Sniegowski K, Bers K, Ryckeboer J, Jaeken P, Spanoghe P, et al. (2012) Minimal pesticide-primed soil inoculum density to secure maximum pesticide degradation efficiency in on-farm biopurification systems. Chemosphere 88(9): 1114-1118.

12. Campos M, Perruchon C, Karas P, Karavasilis D, Diez MC, et al. (2017) Bioaugmentation and rhizosphere-assisted biodegradation as strategies for optimization of the dissipation capacity of biobeds. J Environ Manage 187: 103-110.

13. Saez J, Bigliardo A, Raimondo E, Briceño G, Polti M, Benimeli C (2018) Lindane dissipation in a biomixture: Effect of soil properties and bioaugmentation. Ecotoxicol Environ Sa 156: 97-105.

14. Rodríguez C, Castro V, Chin JS, Ruiz K (2013) On-farm biopurification systems: role of white rot fungi in depuration of pesticide-containing wastewaters. FEMS Microbiol Lett 345(1): 1-12.

15. Niels H, Helweg A, Heinrichson K (2006) Leaching and degradation of 21 pesticides in full-scale model biobeds. Chemosphere 65(11): 22232232. 
16. Tortella GR, Mella Herrera RA, Sousa DZ, Rubilar O, Acuña JJ, et al. (2013) Atrazine dissipation and its impact on the microbial communities and community level physiological profiles in a microcosm simulating the biomixture of on-farm biopurification system. J Hazard Mater 260: 459-467.

17. Diez MC, Leiva B, Gallardo F (2017) Novel insights in biopurification system for pesticides mixture dissipation in repeated applications. Environ Sci Pollut Res Int 25(22): 21440-21450.

18. Rodriguez O, Peralta J, Goonetilleke A, Bandala E (2017) Treatment technologies for emerging contaminants in water: A review. Chemical Engineering Journal 323: 361-380.
19. Jiménez D, Castro V, Fernández E, Briceño S, Masís M, et al. (2018) Expanding the application scope of on-farm biopurification systems: Effect and removal of oxytetracycline in a biomixture. J Hazard Mater 342: 553-560.

20. Cambronero J, Masís M, Quirós J, Lizano V, Mata I, et al. (2018) Removal of herbicides in a biopurification system is not negatively affected by oxytetracycline or fungally pretreated oxytetracycline. Chemosphere 198: 198-203.

\section{Your next submission with Juniper Publishers} will reach you the below assets

- Quality Editorial service

- Swift Peer Review

- Reprints availability

- E-prints Service

- Manuscript Podcast for convenient understanding

- Global attainment for your research

- Manuscript accessibility in different formats

( Pdf, E-pub, Full Text, Audio)

- Unceasing customer service

Track the below URL for one-step submission https://juniperpublishers.com/online-submission.php 